\title{
Synthesis, Antifungal Activity, and Cytotoxicity of AgBr-NP@CTMAB Hybrid and Its Application in PMMA
}

\author{
Qiao-Jun Zhang ${ }^{1,2, *}$ \\ Yue $\mathrm{Liu}^{3, *}$ \\ Wen-Ting Zhang ${ }^{3}$ \\ Jing-Jing Huang ${ }^{2}$ \\ Hao-Hong $\mathrm{Li}^{3}$ \\ You-Guang Lu (D) ${ }^{\prime}$ \\ Ming Zheng ${ }^{2}$ \\ Da-Li Zheng (1)
}

'Fujian Key Laboratory of Oral Diseases, Fujian Biological Materials Engineering and Technology Center of Stomatology, School and Hospital of Stomatology, Fujian Medical University, Fuzhou, Fujian, 350004, People's Republic of China; ${ }^{2}$ Department of Prosthodontics, School and Hospital of Stomatology, Fujian Medical University, Fuzhou, 35000I, People's Republic of China; ${ }^{3}$ College of Chemistry, Fuzhou University, Fuzhou, Fujian, 350I 16, People's Republic of China

*These authors contributed equally to this work

Correspondence: Da-Li Zheng

Fujian Key Laboratory of Oral Diseases, School and Hospital of Stomatology, Fujian Medical University, 88 Jiaotong Road, Fuzhou, 350004, People's Republic of China Tel +86-59l-83720599

Email dalizheng@fjmu.edu.cn

Ming Zheng

Department of Prosthodontics, School and

Hospital of Stomatology, Fujian Medical

University, 246 Yangqiao Middle Road,

Fuzhou, 35000 I, People's Republic of China

Tel +86-59l-8373643I

Email zmdentist@।63.com
Objective: To synthesize and determine the antifungal activity of AgBr-nanoparticles (NP) (a) CTMAB (cetyltrimethyl-ammonium bromide) against Candida albicans (C. albicans) for use in the field of denture cleaning.

Methods: The morphology and structure of AgBr-NP@CTMAB were characterized by IR, UV-Vis, XRD and SEM. The antifungal potential of AgBr-NP@CTMAB against $C$. albicans was determined by colony formation assay and growth curve analysis. PMMA containing AgBr-NP@CTMAB was prepared, and the long-term antifungal efficacy was analyzed. The effect against $C$. albicans biofilm was analyzed by SEM and OD600, and the color changes of the specimens were observed by stereomicroscopy after 1 week of incubation. Cytotoxicity to human oral gingival fibroblasts and oral mucosal epithelial cells was detected by Cell Counting Kit-8 (CCK-8) in vitro.

Results: The compound showed a good crystalline phase, the presence of AgBr nanoparticles and the hybridization of CTMAB+ with AgBr-NPs. AgBr-NP@CTMAB showed significant antifungal activity against $C$. albicans at concentrations of $10 \mu \mathrm{g} / \mathrm{mL}$ and $20 \mu \mathrm{g} / \mathrm{mL}$. PMMA specimens containing AgBr-NP@CTMAB showed no long-term antifungal effect against $C$. albicans biofilm. The clearance rate of $C$. albicans attached to PMMA was $44.73 \%$ after soaking in $10 \mu \mathrm{g} / \mathrm{mL}$ AgBr-NP@CTMAB solution for $30 \mathrm{~min}$ and $91.35 \%$ for $8 \mathrm{~h}$. There was no significant residual cytotoxicity or visual color change after soaking. Significance: AgBr-NP@CTMAB showed promising potential treatment for denture cleaners.

Keywords: C. albicans, AgBr-NP@CTMAB, polymethyl methacrylate, cytotoxicity, biofilm

\section{Introduction}

Polymethyl methacrylate (PMMA) has become the most commonly used denture base because of its sufficient physical, mechanical and aesthetic properties. ${ }^{1}$ However, PMMA also has defects such as multiple pores and high water absorption capacity. $^{2}$ When denture wearers maintain direct contact with oral mucosa for a long time, oral microorganisms easily adhere and accumulate in the unique microenvironment between denture and oral mucosa and form a biofilm on the surface of denture base resins. ${ }^{3}$ Candida albicans ( $C$. albicans) is one of the main factors contributing to infection, forming biofilms ${ }^{4-6}$ and developing into common and recurrent oral disease-denture stomatitis (DS). ${ }^{7}$ There are still problems related to the high cost of antifungal drugs and the side effects of microbial resistance to 
antibiotics. $^{8}$ More seriously, an immune response may occur from denture plaques, and virulence factors released from C. albicans biofilms are high risk factors for opportunistic infections and aspiration pneumonia in the elderly and individuals with weak immune systems. ${ }^{9}$ Therefore, the prevention of $C$. albicans infection leads to a series of clinical problems related to PMMA, which is of great significance for the oral health of denture wearers.

The use of mechanical and chemical methods to control denture organisms or microorganisms is essential to maintain good oral hygiene in denture wearers. The usefulness of mechanical methods for cleaning denture plaque has been clearly demonstrated, but due to conditions such as Parkinson's disease or mental decline in the elderly, these denture wearers have limited motor skills due to neurological diseases, dementia, lack of flexibility and lack of vision ${ }^{10}$ and may not be able to apply daily denture hygiene to the elaborate mechanical brushing of dentures. ${ }^{11}$ It has been reported that the use of inappropriate brushing may cause denture surfaces to become rough and dent, resulting in more $C$. albicans colonizing the tiny pores of PMMA. ${ }^{12}$ The usage of denture cleaners is recommended as a major chemical method and its use is becoming more widespread. ${ }^{3}$ The chemical method is to soak dentures in denture cleaners, which easily removes dental plaque. ${ }^{13}$ For example, neutral peroxide foaming tablets (commercially named Polident) are commonly used in clinical practice. Its antimicrobial mechanism is achieved by chemical cleaning through the oxygen release of neutral enzyme peroxide in water solution. However, this sanitary method is not sufficient to completely eliminate microbial biofilms. ${ }^{14}$ The program of denture cleaning has always been an interesting field to researchers, but there is no ideal method to meet the clinical cleaning requirements.

In recent years, nanomedicine has become a major research field, and many types of nanomaterials have been explored for use in the medical field. Among these, Ag nanoparticles (Agnps) showed superior antibacterial, antifungal, antiviral and other effects. ${ }^{15}$ They are widely used in many fields and are an integral part of many preparations, including soap, deodorant, textiles, electronics, household appliances, cosmetics, and water disinfectants. They are also useful in the food industry for food container production, food sterilization and packaging food supplements. ${ }^{16}$

Quaternary ammonium salts are widely studied in the synthesis of organic antimicrobial materials and have been used for more than 100 years. ${ }^{17}$ According to many previous studies, the preparation process is simple, the synthesis cost is low, and the yield and repetition rate are high. Because of their properties, quaternary ammonium salts are widely used in water treatment, textiles, coatings, medicine and health, as well as other fields. ${ }^{18}$

In the present study, we synthesized $\mathrm{AgBr}$-nanoparticle (a) cetyltrimethyl-ammonium bromide (CTMAB) hybrids and explored their antifungal activity, safety and application in PMMA of AgBr-NP@CTMAB. Through the above experiments, we provide a theoretical basis and guidance for the application prospect of this kind of material. The benefit to denture wearers is a prospect of this study.

\section{Materials and Methods}

\section{Synthesis of AgBr-NP@CTMAB Hybrid Material}

CTMAB·Br $(0.07289 \mathrm{~g}, 0.2 \mathrm{mmol}), \mathrm{KBr}(0.0238 \mathrm{~g}, 0.2$ $\mathrm{mmol})$, and $\mathrm{AgBr}(0.0376 \mathrm{~g}, 0.1 \mathrm{mmol})$ were dissolved in $5 \mathrm{~mL}$ acetonitrile. After stirring for $2 \mathrm{~h}$ at room temperature, the solution was transferred to a small beaker and volatilized at room temperature for 5 days to obtain white needle crystals.

\section{Materials and Physical Measurements}

All chemicals were commercial products and used without further purification. IR spectra were recorded on a Perkin-Elmer Spectrum-2000 FTIR spectrophotometer (4000-400 $\mathrm{cm}^{-1}$ ) from powdered samples spread on $\mathrm{KBr}$ plates. Optical diffuse reflectance spectra were measured on a Perkin-Elmer lambda 900 UV/VIS spectrophotometer equipped with an integrating sphere at $293 \mathrm{~K}$, and $\mathrm{BaSO}_{4}$ plates were used as a reference. Powder XRD patterns were obtained using a Philips X'Pert-MPD diffractometer with $\mathrm{CuK} \alpha$ radiation $(\lambda=1.54056 \AA$ \&́). Highresolution scanning electron microscopy (HR-SEM) measurements of the surface morphologies of films were executed on a Verios G4 UC instrument. ${ }^{19,20}$

\section{Computational Methods}

According to the EDS in SEM, a model with the formula (CTMAB $)_{2}\left(\mathrm{Ag}_{2} \mathrm{Br}_{4}\right)$ was constructed, and full geometry optimization was executed. During the optimization, firstprinciple density-functional theory (DFT) calculations were performed with the Cambridge Sequential Total Energy Package (CASTEP) program. ${ }^{21,22}$ The exchange correlation functional was described by a generalized gradient approximation (GGA) with the PW91 function for 
the solids scheme. A $3 \times 2 \times 2$ Monkhorst-Pack grid with a total number of $6 \mathrm{k}$ points in the irreducible Brillouin zone was used. The number of plane waves included in the basis was determined by a cutoff energy $E_{\mathrm{c}}$ of $489.8 \mathrm{eV}$. The other parameters and convergent criteria were the default values of the CASTEP code.

\section{Fungal Culture}

The $C$. albicans strain from American Type Culture Collection (ATCC, \#90029) was used as the model pathogen for the antifungal activity experiments. The fungi from stock cultures were cultivated in Sabouraud dextrose agar (SDA) plates and incubated at $37{ }^{\circ} \mathrm{C}$ for $48 \mathrm{~h}^{23}$ One loopful of this young culture was transferred to $10 \mathrm{~mL}$ of yeast extract peptone dextrose (YPD) medium and incubated at $37{ }^{\circ} \mathrm{C}$ for $24 \mathrm{~h}$. The concentration of the bacterial liquid was determined by the absorbance at $600 \mathrm{~nm}$ (OD600). ${ }^{24}$

\section{Colony Formation Assay}

Twenty microliters of fungal solution with approximately $1 \times 10^{4}$ colony forming units per $\mathrm{mL}(\mathrm{CFU} / \mathrm{mL})$ of C. albicans was spread on SDA agar plates containing different concentrations of AgBr-NP@CTMAB. After incubating at $37{ }^{\circ} \mathrm{C}$ for $48 \mathrm{~h}$, the yeast colonies were photographed, and the number of colonies was counted manually.

\section{Growth Curve Assay}

Two hundred microliters of the suspension of $C$. albicans$\left(10^{4} \mathrm{CFU} / \mathrm{mL}\right)$ in YPD broth medium were added to each well of a 96-well plate, and different concentrations of AgBr-NP@CTMAB were added to the wells. The growth of $C$. albicans was assessed using a Bioscreen C Automated Microbiology Growth Curve Analysis System (Turku, Finland) at $37{ }^{\circ} \mathrm{C}$ under shaking at $200 \mathrm{rpm}$. The OD values at $600 \mathrm{~nm}$ were measured every hour for up to $48 \mathrm{~h}^{25}$

\section{Cell Culture}

Human oral mucosal epithelial cells (HOEC, Beijing Beina Biotechnology, BNCC340217) were cultured in Dulbecco's modified Eagle's medium containing 10\% FBS. Primary human gingival fibroblasts (HGFs) were mechanically isolated from fragments of gingival tissues obtained from patients (ages 20 to 30) with healthy periodontium who were subjected to surgery for tooth extraction with informed consent. Tissues were processed by enzymatic dispersion to produce primary cell cultures, and cells were maintained in Dulbecco's modified Eagle's medium (DMEM) containing 10\% fetal bovine serum (FBS) and antibiotic/antimycotic (penicillin, streptomycin, amphotericin; Gibco/BRL). Cells between passages 3 and 6 were used for experiments. ${ }^{26}$ This study was approved by the Institutional Review Board of Fujian Medical University School and Hospital of Stomatology (Approval Number: FMUSS18-031).

\section{Cytotoxicity Assay for AgBr-NP@CTMAB}

HOECs and HGFs were cultured in a 96-well plate at a density of $4 \times 10^{3}$ and $2 \times 10^{3}$ cells/well, respectively, and $24 \mathrm{~h}$ later, different concentrations of AgBr-NP (a) CTMAB were added. After culture for $72 \mathrm{~h}, 10 \mu \mathrm{L}$ of CCK-8 reagent was added to each well, and the absorbance at $450 \mathrm{~nm}$ was measured after 1 $\mathrm{h}$ incubation.

\section{Fabrication of Specimen}

The AgBr-NP@CTMAB particles were incorporated at $0.25,0.50$ and $1.00 \%$ (wt/wt) with the PMMA powder and mixed manually under constant agitation for $10 \mathrm{~min}$ to obtain an adequate particle distribution. Then, the mixture powders were dispersed in the MMA liquid and immediately mixed together under stirring by the same operator. The powder $(\mathrm{g})$-to-liquid $(\mathrm{mL})$ ratio was maintained as recommended by the manufacturers. ${ }^{27}$ After homogenization, the mixture was injected into a stainlesssteel mold during the plastic phase. ${ }^{28}$ After lowtemperature polymerization $\left(55 \pm 5^{\circ} \mathrm{C}, 30 \mathrm{~min}\right.$, Multicure, Vertex, Zeist, Netherlands), specimens were polished with abrasive papers 600 up to 1000 grit under water cooling. Then, the specimens $(10.0 \mathrm{~mm} \times 10.0 \mathrm{~mm} \times 2.0 \mathrm{~mm})$ were scrubbed with water and ultrasonically cleaned for $30 \mathrm{~min}$ before immersion in PBS $52 \pm 2 \mathrm{~h}$ at $37^{\circ} \mathrm{C} .{ }^{29}$ The morphology of the modified PMMA-based specimens was analyzed by a stereomicroscope (Magellan 400L; FEI Co) before testing.

\section{Surface Roughness Measurement}

The surface roughness of all specimens was measured with a profilometer (DSF600, Kosaka Laboratory Ltd, Japan). Three measurements were made for each specimen. According to the JIS'13/ISO'97 standard, the 
resolution was $0.01 \mathrm{~mm}$, the interval (cut off length) was $0.8 \mathrm{~mm}$, the transverse length was $2.0 \mathrm{~mm}$, and the stylus speed was $0.5 \mathrm{~mm} / \mathrm{s}$. The $\operatorname{Ra}(\mu \mathrm{m})$ value of that specimen was selected as the decision parameter. All measurements were recorded by one operator. ${ }^{30}$

\section{Vickers Microhardness Measurement}

Vickers microhardness was measured by using a hardness tester (HX-1000TM, Taiming, Shanghai, China). The diamond indenter point was kept on the surface of specimens for 30 seconds with a 300-gram load. Three points on the diagonal line of each sample are pressurized. The measured values were taken as the $\mathrm{HV}$ of the specimens. ${ }^{2}$

\section{Antifungal Effect of AgBr-NP@CTMAB/ PMMA}

The antifungal activity of the AgBr-NP@CTMAB/PMMA specimens was detected by direct contact test (DCT). ${ }^{31}$ Conventional PMMA served as the negative control. The specimens were placed in 12-well plates, and $2 \mathrm{~mL}$ of $1 \times 10^{7} \mathrm{CFU} / \mathrm{mL}$ of $C$. albicans suspension was added into each well. After incubation at $37{ }^{\circ} \mathrm{C}$ for $24 \mathrm{~h}$, the fungal biofilms on the specimens were gently washed 3 times with PBS and placed in a centrifuge tube containing $2 \mathrm{~mL}$ PBS. Agitation of these tubes three times $(2 \mathrm{~min}$ each time) in a vortex-type agitator allowed the dispersion of the $C$. albicans adhered to the surface of PMMA specimens. Two milliliters of fresh PBS were used in each agitation, and the PBS after 3 shocks was finally mixed. ${ }^{32}$ To estimate colony formation, fungal suspensions from each specimen were diluted serially, and an aliquot of $20 \mu \mathrm{L}$ was inoculated onto SDA plates.

For the reusability test (cycling), the specimens after the first antifungal test were rinsed thoroughly with water and soaked in alcohol for $30 \mathrm{~min}$. The specimens were air dried, sterilized under ultraviolet radiation for 30 min on each side ${ }^{33}$ and used for the antifungal test as before.

\section{Cytotoxicity Assay for}

\section{AgBr-NP@CTMAB/PMMA}

The eluent was prepared by soaking each specimen in $1 \mathrm{~mL}$ of DMEM in 12-well cell plates at $37{ }^{\circ} \mathrm{C}$ for 72

$\mathrm{h}$. The eluent was filtered for sterilization and then stored at $4{ }^{\circ} \mathrm{C}$ before use. ${ }^{34} \mathrm{HGF}$ and HOEC were seeded in the wells of 96 -well plates at a density of $4 \times 10^{3}$ cells and
$2 \times 10^{3}$ cells per well, respectively. Twenty-four hours later, the culture medium in the 96-well plates was removed and replaced with $100 \mu \mathrm{L}$ eluent of PMMA. The cells were cultured for $72 \mathrm{~h}$, and the cell viability was measured using CCK-8 reagent. ${ }^{35}$

\section{Anti-Biofilm Activity of AgBr-NP@CTMAB}

The PMMA specimens were then sterilized under ultraviolet radiation for $30 \mathrm{~min}$ on each side, immersed in a 24-well plate containing $C$. albicans suspension at a concentration of $3 \times 10^{6} \mathrm{CFU} / \mathrm{mL}$, incubated at a constant temperature of $28{ }^{\circ} \mathrm{C}$ with a rotating speed of $180 \mathrm{r} / \mathrm{min}$ for $90 \mathrm{~min}$, and then placed in an incubator at $37{ }^{\circ} \mathrm{C}$ for $24 \mathrm{~h}^{36}$ After washing each side with PBS twice, the samples were placed into different concentrations of solutions, soaking for $30 \mathrm{~min}$ or $8 \mathrm{~h}$ each, with PBS as the control. The soaked PMMA specimens were washed, dried and placed in a centrifuge tube containing $2 \mathrm{~mL}$ PBS. Agitation of these tubes three times $(2 \mathrm{~min}$ each time) in a vortex-type agitator allowed the dispersion of the C. albicans adhered to the surface of PMMA specimens. ${ }^{37}$ Two milliliters of fresh PBS was used at each time of agitation, and the PBS after 3 shocks was finally mixed to determine the OD600.

\section{Scanning Electron Microscopy}

Biofilms of $C$. albicans were grown in 24-well plates containing PMMA for $24 \mathrm{~h}$ and then treated with PBS, Polident, 10 and $20 \mu \mathrm{g} / \mathrm{mL}$ of AgBr-NP@CTMAB for 8 h. At the end of the incubation period, specimens were removed and washed with PBS three times. Afterwards, biofilms were qualitatively analyzed by scanning electron microscopy ${ }^{4}$ (Quanta 250, Thermo-Fisher Scientific, USA). Specimens were fixed in $2.5 \%$ glutaraldehyde at $4{ }^{\circ} \mathrm{C}$ and dehydrated in ascending ethanol ranging from 50 to $100 \%$ for $10 \mathrm{~min}$. The specimens were then sputter coated with gold using a sputter coater and imaged via SEM with an accelerating voltage of 15 $\mathrm{keV}$, and SEM images of surfaces were recorded after fixation. ${ }^{38}$

\section{Residual Cytotoxicity}

Each sterilized specimen was immersed in PBS, Polident, 10 $\mu \mathrm{g} / \mathrm{mL}$ and $20 \mu \mathrm{g} / \mathrm{mL}$ of AgBr-NP@CTMAB solution on a 12-well plate. After $8 \mathrm{~h}$, each sample was washed three times in PBS to remove the excess soaking solution and then 
placed in a new culture plate. The extract was prepared by soaking each specimen in $1 \mathrm{~mL}$ of DMEM in 12-well cell plates at $37{ }^{\circ} \mathrm{C}$ for $24 \mathrm{~h} .{ }^{39} \mathrm{An}$ in vitro residual cytotoxicity assay was carried out by exposing HOEC and HGF cells as described above.

\section{Color Stability of Specimens}

During the experiment, all specimens were immersed for 8 $\mathrm{h}$ in solutions and then for $16 \mathrm{~h}$ in artificial saliva, simulating night disinfection and daily use of the prosthesis. After the next immersion period cycle, the specimens were rinsed in water to remove excess disinfectant solution. The specimens were stored for 7 days, and the solutions were changed daily. ${ }^{40}$ Color stability tested by stereomicroscopy (CMS; Leica Microsystems).

\section{Statistical Analysis}

All experiments were performed three times to obtain representative results. Data were analyzed using Prism 5.0 software (GraphPad) by one-way analysis of variance (one-way ANOVA) followed by Tukey's multiple comparison test, with the value of significance set at $p<0.05$.

\section{Results}

\section{Synthesis and Characterization of} AgBr-NP@CTMAB

The AgBr-NP@CTMAB hybrid material was synthesized, and the material characterization was analyzed by IR spectroscopy. All IR peaks (cm ${ }^{-1}$ ): 3013(w), 2094(s), 2852(s), 1467 (s), 1114(s), 1055(w), 1034(w), 960(s), 902(s), 723(s) corresponded to the characteristic vibrations of C-C, C-N and $\mathrm{C}-\mathrm{H}$ bonds in $\mathrm{CTMAB}^{+}$(Figure 1A), respectively. UV-Vis adsorption at $239 \mathrm{~nm}$ also hinted at the presence of $\mathrm{CTMAB}^{+}$ (Figure 1B). In the PXRD pattern (Figure 1C), the $2 \theta$ values of $25.16,29.58$, and $47.61^{\circ}$ suggested the presence of $\mathrm{AgBr}$ nanoparticles. The HR-SEM diagram (Figure 2) illustrated its good crystalline phase, and surface EDS analysis further verified the hybridization of $\mathrm{CTMAB}^{+}$with $\mathrm{AgBr}-\mathrm{NP}$.

According to the EDS in SEM (Figure 2), a molecular simulation based on the DFT method using the CASTEP program was also conducted to disclose the electronic structure and geometry of AgBr-NP@CTMAB. Upon full optimization, the AgBr-NP@CTMAB hybrid can be described as the model of $(\mathrm{CTMAB})_{2}\left(\mathrm{Ag}_{2} \mathrm{Br}_{4}\right)$ (Figure
A

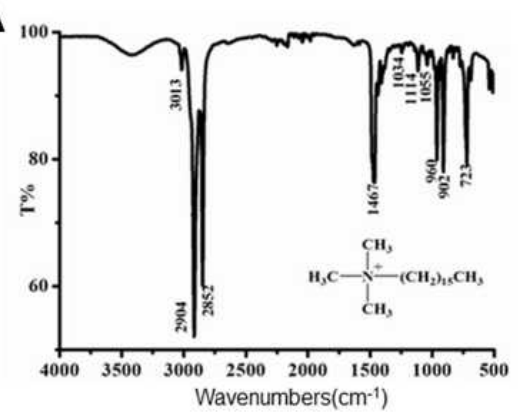

B

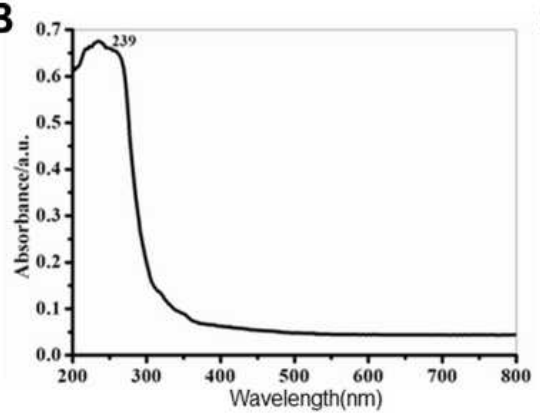

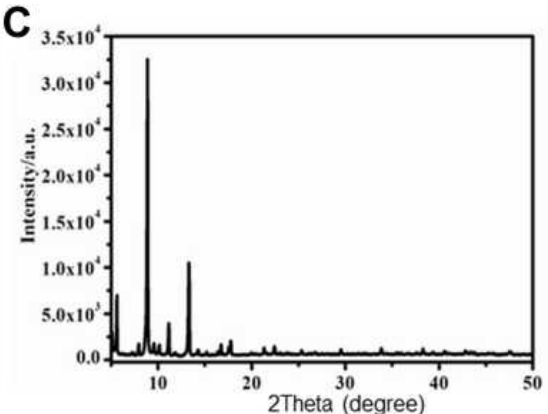

Figure I IR spectrum (A), UV-Vis spectrum (B), and PXRD pattern (C) of nanohybrid material.

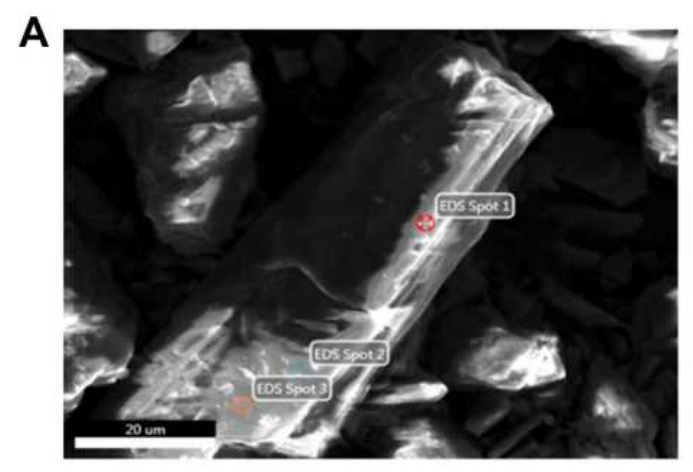

B

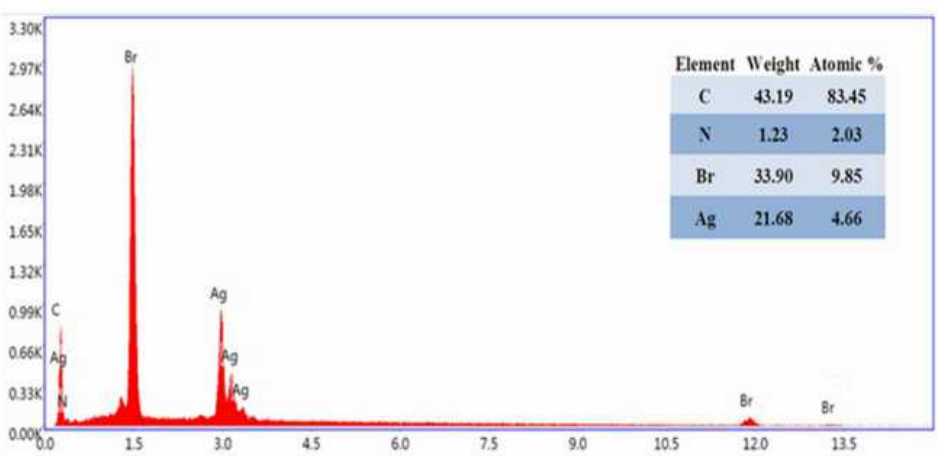

Figure 2 SEM (A) and EDS (B) diagrams of the nanohybrid material. 
3A). In this model, $\mathrm{Ag}$ is in two coordinated environments, the $\mathrm{AgBr}_{3}$ triangle and the $\mathrm{AgBr}_{4}$ tetrahedron. $\mathrm{A} \mathrm{Ag}_{4} \mathrm{Br}_{8}$ tetramer was built from edge-sharing of two $\mathrm{AgBr}_{3}$ triangles and $\mathrm{AgBr}_{4}$ tetrahedrons. Specifically, the CTMAB cations are generally linear, and this large steric hindrance leads to the poor adherence of the AgBr-NP@CTMAB hybrid with PMMA. The band structure and partial density of states (PDOS) are given in Figure 3B. A calculated direct band gap of $1.12 \mathrm{eV}$ was observed. PDOS indicated that the valence-band maximum mainly results from the mixed nonbonding states of $\mathrm{Br}-4 p / \mathrm{Ag}-4 \mathrm{~d}$ and the p-orbital of $\mathrm{CMTAB}^{+}$, but at the bottom of the conductive band, the $p^{*}$ anti-bonding orbitals of $\mathrm{CMTAB}^{+}$dominate (right of Figure 3B).

\section{Solutions of AgBr-NP@CTMAB Inhibit the Growth of Candida albicans Plankton}

Next, we explored the effect of AgBr-NP@CTMAB on planktonic Candida albicans. In the colony formation assay, AgBr-NP@CTMAB showed excellent antifungal activity by decreasing the number and size of the colonies of $C$. albicans in a dose-dependent manner. The antifungal rates of 5, 10, 20 and $40 \mu \mathrm{g} / \mathrm{mL}$ AgBr-NP@CTMAB were $31.32 \pm 4.95 \%, 53.38 \pm 8.08 \%$, and $97.36 \pm 2.21 \%$, respectively, which were statistically significant compared with the blank control group (Figure $4 \mathrm{~A}$ and $\mathrm{B}, \mathrm{P}<0.05$ ). No colonies were observed when the concentration was greater than $20 \mu \mathrm{g} / \mathrm{mL}$. According to the automatic growth curve analyzer, $2 \mu \mathrm{g} / \mathrm{mL}$ AgBr-NP@CTMAB slightly extended the lag phase of $C$. albicans, while at $5 \mu \mathrm{g} / \mathrm{mL}$, the lag phase of $C$. albicans was obviously prolonged by 5 $\mathrm{h}$ (Figure 4C). When the concentration of $\mathrm{AgBr}-\mathrm{NP}$ (a) CTMAB reached $10 \mu \mathrm{g} / \mathrm{mL}$, the OD600 value slightly increased only in the last several hours of the $48 \mathrm{~h}$, and no significant microorganism growth was found at the concentration of $20 \mu \mathrm{g} / \mathrm{mL}$.

\section{AgBr-NP@CTMAB Was Not Suitable to Be Incorporated into PMMA}

Because of the excellent antifungal activity of AgBr-NP @CTMAB, we next explored whether it can be incorporated into PMMA specimens to improve the antifungal effect and prevent biofilm accumulation. PMMA specimens were fabricated with and without the incorporation of $0.25 \%, 0.5 \%$ or 1.0\% AgBr-NP@CTMAB. The polymerization and the surface roughness values of PMMA specimens were not affected by the incorporation of AgBr-NP@CTMAB
(Figure 5A), while the microhardness values of PMMA with higher concentrations of AgBr-NP@CTMAB $(0.5,1.0$ $\mathrm{wt} \%)$ were slightly higher than those of the specimens without AgBr-NP@CTMAB (Figure 5B, P<0.05). The incorporation of AgBr-NP@CTMAB inhibited biofilm accumulation on the PMMA surface (Figure $5 \mathrm{C}$ and $\mathrm{E}$ ), but when we reused the PMMA specimens for antifungal assays, we found that the inhibition effect was attenuated (Figure 5D and $\mathrm{F}$ ) the second time and disappeared after 3 times of usage (data not shown), which indicated that the effective antifungal component was quickly released from the PMMA specimens. Furthermore, the incorporation of AgBr-NP (a) CTMAB significantly decreased the viability of HGFs and HOEC cells (Figure 6A and B), which also indicated its release from PMMA specimens and the high cytotoxicity of AgBr-NP@CTMAB. Additionally, there were some white visible spots on the AgBr-NP@CTMAB-containing PMMA specimens due to the uneven mixture (Figure 6C). Based on the short-term antifungal activity results, high cytotoxicity and uneven mixture, we concluded that AgBr-NP@CTMAB was not suitable for incorporation into PMMA.

\section{AgBr-NP@CTMAB Solution Efficiently Inhibited Biofilm Formation on PMMA Specimens}

Next, we explored whether AgBr-NP@CTMAB solution can serve as denture cleaner similar to Polident. The PMMA specimens with a biofilm formed by $C$. albicans were soaked for $30 \mathrm{~min}$ or $8 \mathrm{~h}$ (overnight) in different concentrations of AgBr-NP@CTMAB, as well as PBS for the negative control and Polident (freshly prepared as recommended by the manufacturer) for the positive control. The results showed that AgBr-NP@CTMAB inhibited biofilm formation on PMMA in a dose-dependent manner (Figure $7 \mathrm{~A}$ and $\mathrm{B}$ ), and the biofilm clearance rate was $76.00 \%$ when treated with $20 \mu \mathrm{g} / \mathrm{mL}$ AgBr-NP@CTMAB for $30 \mathrm{~min}$, similar to that of Polident (79.44\%, $\mathrm{P}>0.05$ compared with $20 \mu \mathrm{g} / \mathrm{mL}$ AgBr-NP@CTMAB). After soaking for $8 \mathrm{~h}$, the C. albicans biofilm was inhibited by $91.35 \%, 92.57 \%$ and $92.73 \%$ by solutions of $10 \mu \mathrm{g} / \mathrm{mL}$ and $20 \mu \mathrm{g} / \mathrm{mL}$ AgBr-NP (a) CTMAB and Polident, respectively ( $\mathrm{P}>0.05$ between these 3 groups by one way ANOVA). AgBr-NP@CTMAB at concentrations of $10 \mu \mathrm{g} / \mathrm{mL}$ and $20 \mu \mathrm{g} / \mathrm{mL}$ almost completely diminished the biofilm formed on the PMMA surfaces compared with the control. The SEM images (Figure 7C) showed that the C. albicans biofilm layer effectively spread on the specimens by penetrating into their notched surfaces 


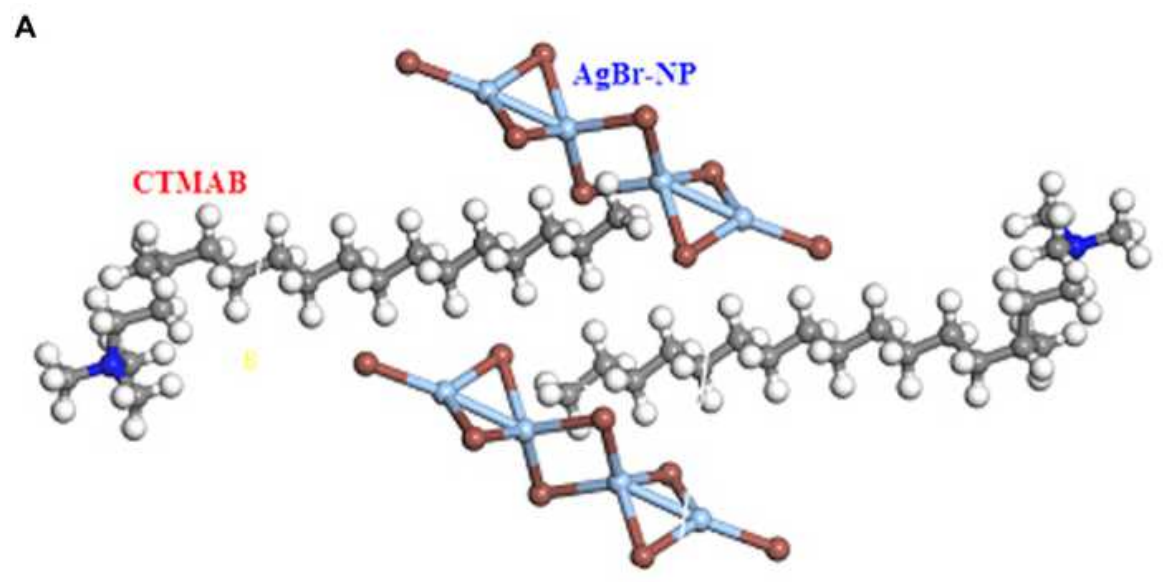

B
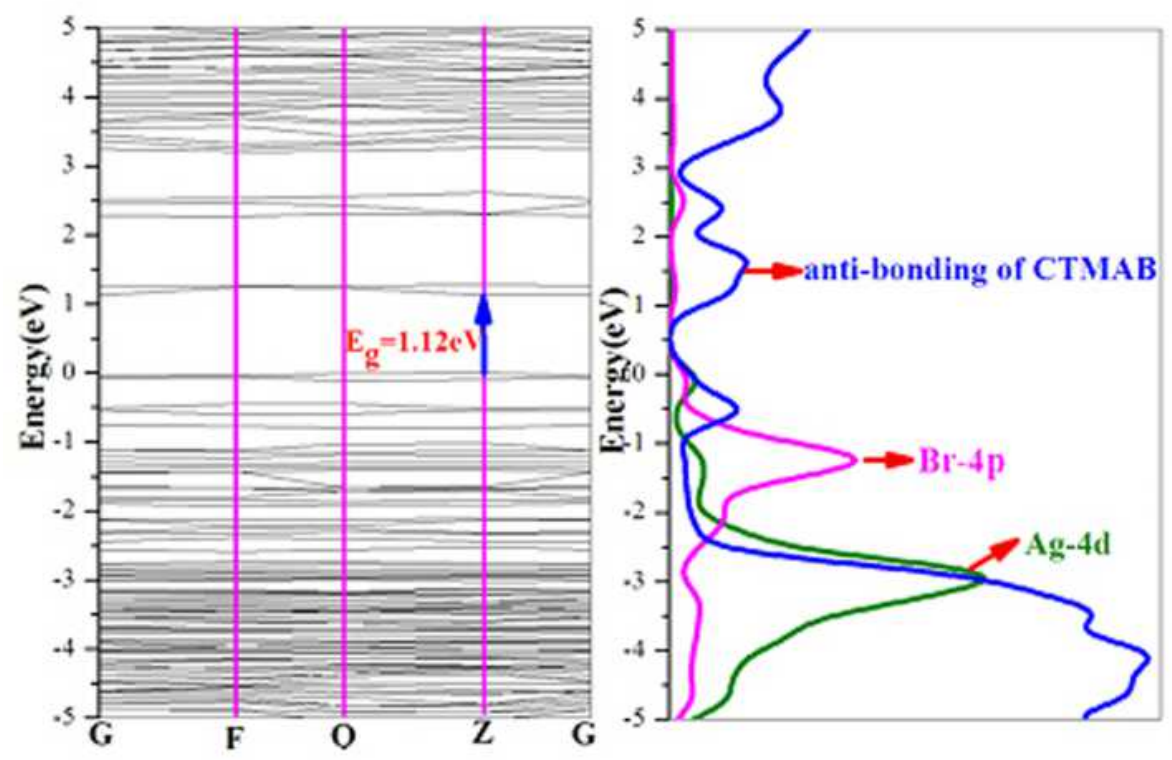

Figure 3 The geometry of $(C T M A B)_{2}\left(\mathrm{Ag}_{2} \mathrm{Br}_{4}\right)(\mathbf{A})$; band structure (left) and projected density of states (right) for $(\mathrm{CTMAB})_{2}\left(\mathrm{Ag}_{2} \mathrm{Br}_{4}\right)(\mathbf{B})$.

in the control group, whereas the biofilm was destroyed by the AgBr-NP@CTMAB solutions and Polident, and there were only some small colonies attached on the surfaces of PMMA. Although directly added to culture medium, $\mathrm{AgBr}$ NP@CTMAB at the effective concentrations $(10 \mu \mathrm{g} / \mathrm{mL}$ and $20 \mu \mathrm{g} / \mathrm{mL}$ ), as well as Polident, showed high cytotoxicity to HGFs and HOEC cells (Figure 8A and $\mathrm{B}, \mathrm{P}<0.01$ when compared these groups with control), but there was no detectable residual cytotoxicity left after washing 3 times with PBS (Figure $8 \mathrm{C}$ and $\mathrm{D}, \mathrm{P}>0.05$ among all the groups). To detect whether the immersion in the solution containing AgBr-NP (a) CTMAB cause surface deterioration of denture-base resin, the PMMA specimens were immersed for $8 \mathrm{~h}$ in solutions and then for $16 \mathrm{~h}$ in artificial saliva, and the results showed there was no obvious visual color change after soaking for one week (Figure 8E).

\section{Discussion}

Ag-based nanoparticles are common inorganic antimicrobial agents. $\mathrm{Kumar}^{41}$ reported the antibacterial potential of $\mathrm{Ag}$ and $\mathrm{Ag}$ compound nanoparticles against a variety of foodborne pathogenic bacteria and different Candida species. Moreover, because of its small size, scanning transmission electron microscopy (STEM) has proven that Agnp has penetrated bacteria and fungi, causing damage in microorganisms by interacting with 


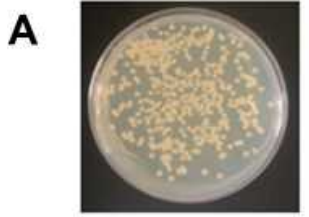

$0 \mu \mathrm{g} / \mathrm{mL}$

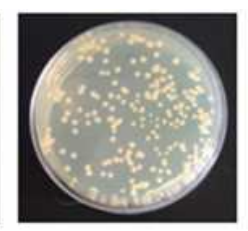

$5 \mu \mathrm{g} / \mathrm{mL}$

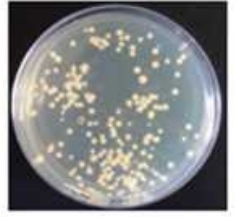

$10 \mu \mathrm{g} / \mathrm{mL}$

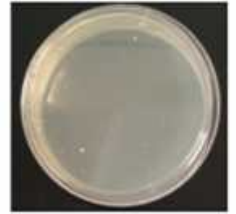

$20 \mathrm{ug} / \mathrm{mL}$

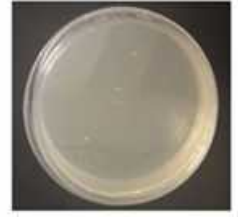

$40 \mathrm{ug} / \mathrm{mL}$
B

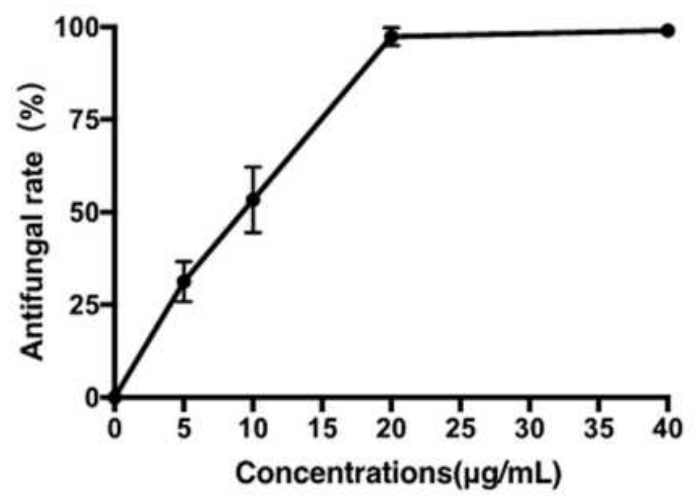

C

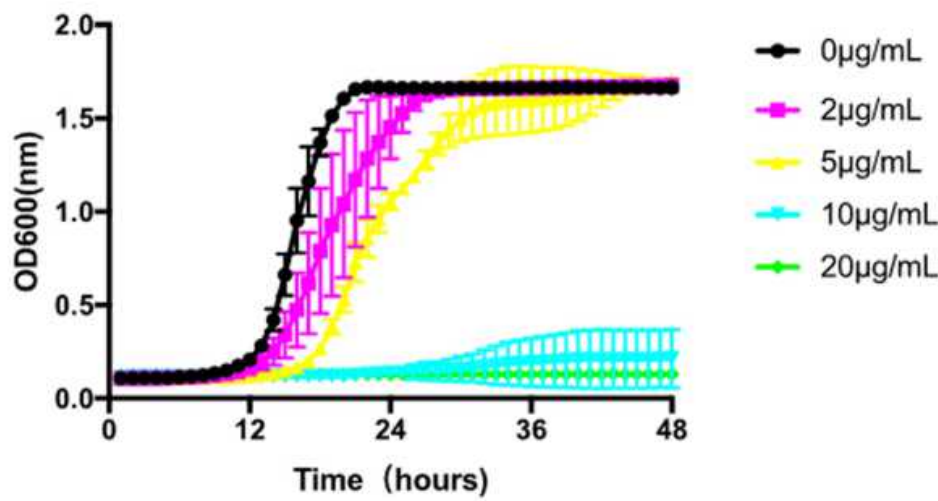

Figure 4 Agar plates of $C$. albicans cultured for $48 \mathrm{~h}$ in SDA with various concentrations of AgBr-NP@CTMAB (A). The anti-C. albicans activities evaluated via colonycounting methods (B). The growth curves of $C$. albicans in the presence of AgBr-NP@CTMAB were recorded at an OD600 value (C). The data are shown as the means \pm SD. Bars represent standard deviations of three independent experiments.

phosphorus and sulfur-containing compounds such as DNA. Petr ${ }^{42}$ further compared the antibacterial activity of $\mathrm{Ag}$ nanoparticles and $\mathrm{AgBr}$ nanoparticles against gram-positive and gram-negative bacteria and several Candida species. The results showed that Ag nanoparticles had the best antibacterial activity against grampositive bacteria, while AgBr-NPs had better antibacterial activity against gram-negative bacteria and experimental yeast strains.

Quaternary ammonium salt compounds in organic antimicrobial agents have antibacterial and antifungal properties. CTMAB is a surfactant that belongs to the quaternary ammonium salts of organic antimicrobial agents. Previous investigations have proven that it is a promising material for the remediation of contaminated farmland. ${ }^{43}$ The mixtures of CTMAB reduce the transfer of pollutants from soil to plants, which ensures the safety of agricultural production growing in contaminated soil. However, there are few reports on the application of CTMAB in the field of medicine.

In the present study, we synthesized $\mathrm{AgBr}$ nanoparticle@CTMAB hybrid compounds and found that the composite materials show excellent antifungal efficiency by inhibiting both the growth of planktonic cells and the formation of $C$. albicans biofilms, but the mechanism of how nanoparticles cause the death of C. albicans should be further studied. The electronic structure (Figure 3 ) suggests that the antifungal activity of the hybrid is the synergistic effect involving CMTAB + and AgBr-NP.

Although PMMA is widely used in denture base resin, it has limitations due to its lack of antimicrobial and antifungal activity. Several attempts to incorporate different compounds into PMMA to provide antifungal effects have been made for clinical use. Zhang ${ }^{44}$ evaluated the antifungal properties, cytotoxicity to human dental pulp cells (HDPCs) and mechanical properties of silver bromide/cationic polymer nanocomposites added to PMMA. The experimental data showed that the addition of $\mathrm{AgBr} / \mathrm{NPVP}$ gives a strong and lasting antifungal effect on C. albicans with low toxicity to HDPCs and no significant change in mechanical properties compared with the control group. After revealing the excellent antifungal activity of AgBr-NP@CTMAB, we next tried to incorporate it into PMMA specimens to improve the antifungal effect. The incorporation of up to $1 \%$ 


\section{A}

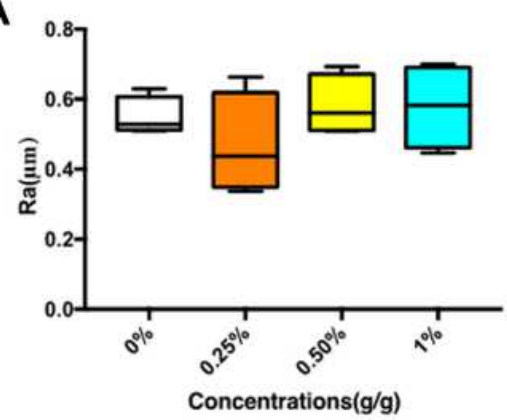

B

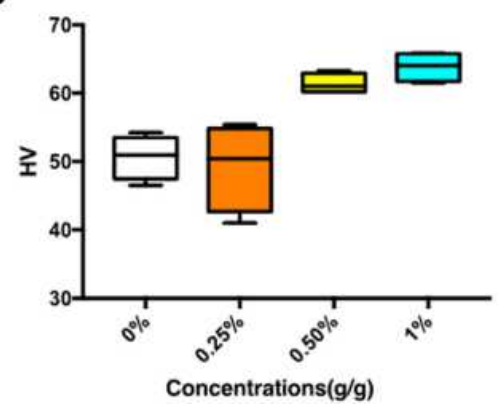

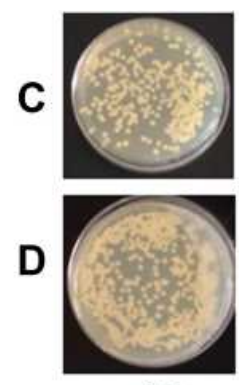

$0 \%$

E

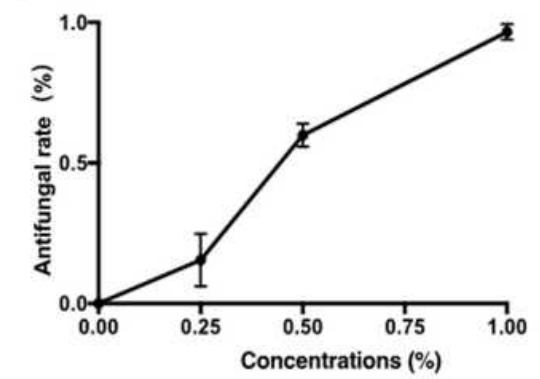

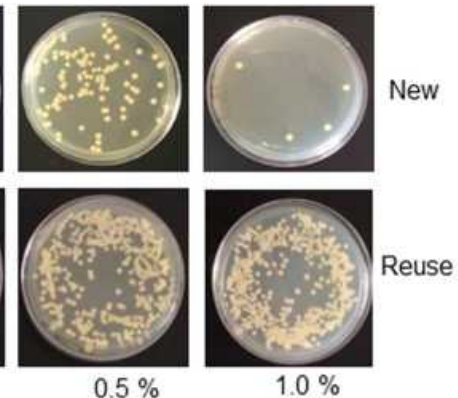

$\mathbf{F}$

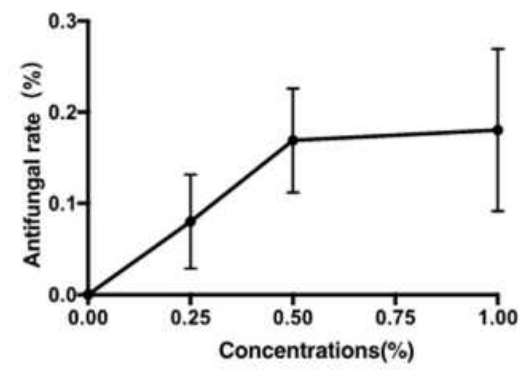

Figure 5 Incorporation of $\mathrm{AgBr}-\mathrm{NP} @ \mathrm{CTMAB}$ into PMMA resin and its antifungal activity. Mechanical properties of PMMA resin with or without $\mathrm{AgBr}-\mathrm{NP} @ \mathrm{CTMAB}$ such as surface roughness $(\mathbf{A})$ and Vickers microhardness value $(\mathbf{B})$ were measured. The antifungal activity of $0.25,0.50$, and I.00 wt\% AgBr-NP@CTMAB incorporated into PMMA on C. albicans biofilm was tested using the freshly prepared specimens ( $\mathbf{C}$ and $\mathbf{E}$ ) and reused ones ( $\mathbf{D}$ and $\mathbf{F})$. The data are presented as the means \pm SD. Error bars show the standard deviation (SD).

AgBr-NP@CTMAB did not affect the polymerization of PMMA and did not decrease the surface roughness and microhardness of the PMMA specimens. The results also indicated that AgBr-NP@CTMAB containing PMMA showed excellent antifungal activity in the beginning but failed to yield long-term antifungal effects, which may due to the quick release of effective antifungal components from PMMA specimens. The eluent of PMMA specimens containing AgBr-NP (a) CTMAB also showed high cytotoxicity to HGFs and HOEC cells. The defects in the long-term antifungal activity and cytotoxicity of AgBr-NP@CTMAB dictated that it was not suitable for incorporation into PMMA.

There are many existing methods to clean dentures, such as mechanical, chemical or a combination of methods. ${ }^{10}$ Mechanical procedures include toothpaste brushing the denture base, which is the most commonly used method. Because of the characteristics of irregular tissue surfaces and holes in the denture base, the cleaning effect of simple mechanical methods such as brushing teeth is limited. However, effective removal of biofilms requires a certain degree of artificial dexterity, which is often lacking in the elderly. ${ }^{11}$ Therefore, chemical cleaning, such as soaking in denture cleaner solution, is considered to be a feasible alternative. ${ }^{3}$ The effectiveness of chemical cleansing to control $C$. albicans biofilms has been shown in many studies. Polidents are available as commercial products, which can easily provide enough cleansing without causing damage to denture resins. ${ }^{14}$ According to the manufacturer's instructions, $5 \mathrm{~min}$ of soaking or overnight soaking can kill most microbes. In the present study, we found that the solution of 20 $\mu \mathrm{g} / \mathrm{mL}$ AgBr-NP@CTMAB showed similar antifungal activity to inhibit biofilm formation as Polident. When added directly to cell culture medium, AgBr-NP @CTMAB, as well as Polident, showed high cytotoxicity to HGFs and HOEC cells. However, there was no detectable residual cytotoxicity left after washing 3 times with PBS, which indicated its safety when used correctly.

Chemical cleaners may cause acrylic bleaching and metal corrosion of dentures. ${ }^{45}$ Color stability is an important physical and mechanical property factor of a resin base, indicating its applicability, aging or damage over a period of time. In the present study, we found no unacceptable discoloration of PMMA specimens after soaking these solutions for one week. 


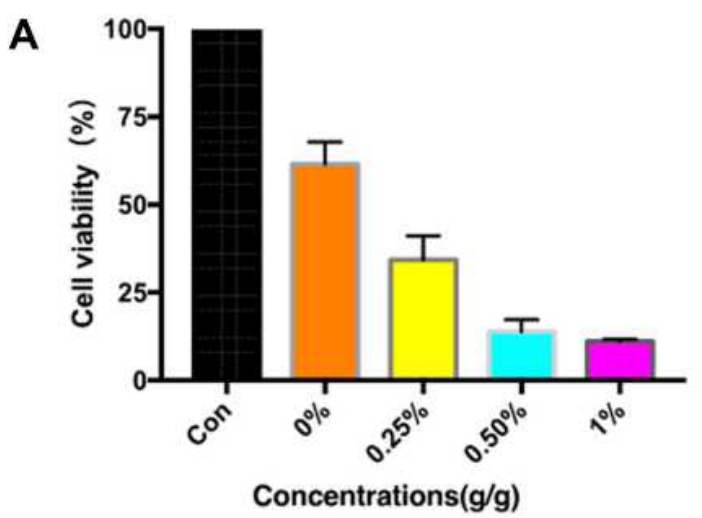

B

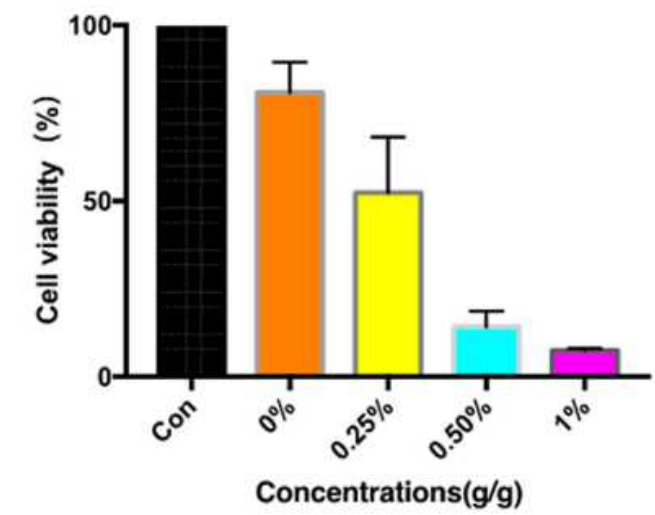

C

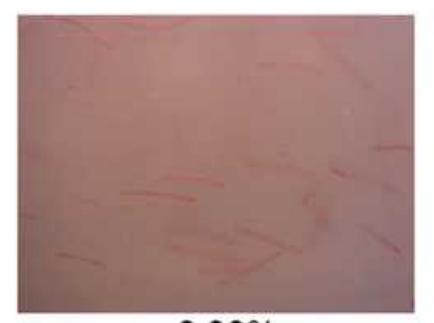

$0.00 \%$

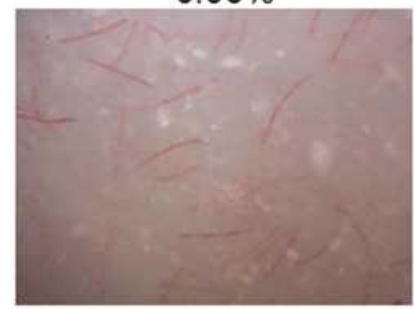

$0.50 \%$

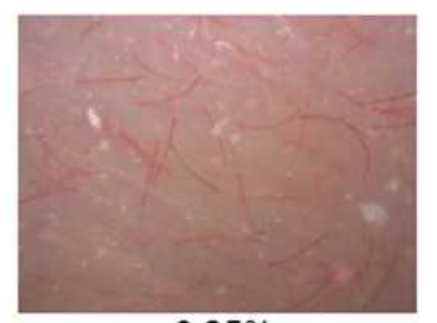

$0.25 \%$

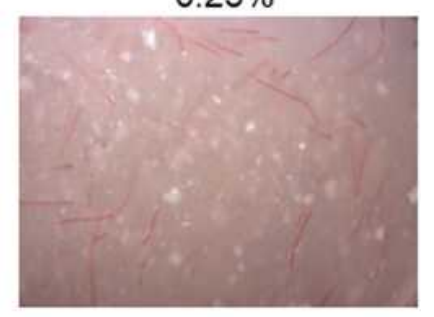

$1.00 \%$

Figure 6 Incorporation of AgBr-NP@CTMAB into PMMA specimens and its cytotoxicity and appearance. (A and B) The cell viability of HOECs (A) and HGFs (B) were measured after culture for $72 \mathrm{~h}$ with the extracts of AgBr-NP@CTMAB/PMMA incorporated specimens. The representative means and SDs were recorded after independent triplicate experiments. (C) The representative images of the PMMA specimens incorporated with AgBr-NP@CTMAB/PMMA.

\section{Conclusions}

AgBr-NP@CTMAB could effectively suppress both the growth of planktonic cells and the formation of C. albicans biofilms. Due to its quick release and cytotoxicity, AgBr-NP@CTMAB is not suited to be incorporated into PMMA specimens, but it may be an effective alternative measure for cleansing biofilms from denture surfaces, with nearly equal efficiency as Polident in the elimination of vital cells from biofilms. In addition, immersion in the solution containing AgBr-NP@CTMAB does not cause surface deterioration of denture-base specimens, and it was deemed safe as a soak solution, as the experiment showed no toxic residue on the denture surface. The single ingredient of AgBr-NP@CTMAB can reach the equal efficiency of Polident, which contains four active ingredients, indicating that AgBr-NP@CTMAB has great potential as a new component of denture cleanser.

\section{Data Sharing Statement}

All data generated or analyzed during this study are included in this published article.

\section{Ethics Approval and Consent to Participate}

This study was approved by the Institutional Review Board of Fujian Medical University School and Hospital of Stomatology (Approval Number: FMUSS-18-031), and written informed consent was obtained from each participant. The study was carried out in accordance with the guidelines for the care and use of human specimens and animals, including in the approved protocol.

\section{Acknowledgments}

This work was financially supported by Key Laboratory Foundation of Stomatology of Fujian Province University (Grant number: 2019kq03) and Startup funding of Fujian Medical University (Grant number: 2019QH1130). The funding bodies had no role in the design of the study and collection, analysis, and interpretation of data and in writing the manuscript. We thank Mr. Lixin Zheng (Georgia Institute of Technology) for the language editing for this manuscript. 


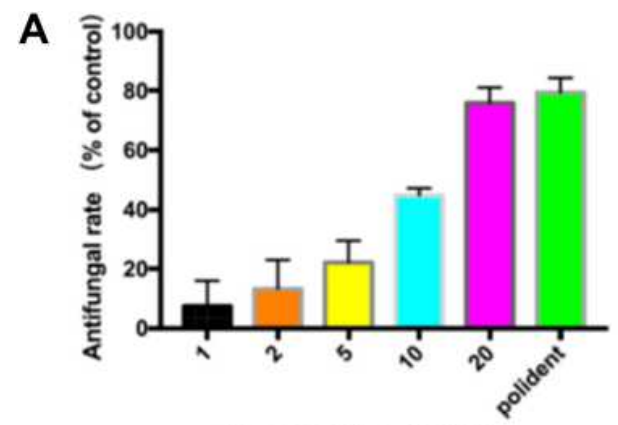

Concentrations $(\mu \mathrm{g} / \mathrm{mL})$

B

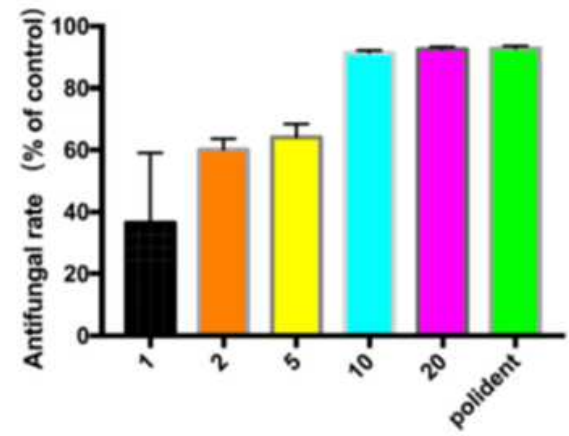

Concentrations $(\mu \mathrm{g} / \mathrm{mL})$

C

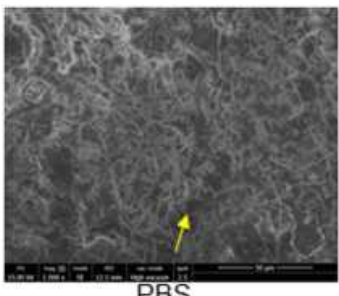

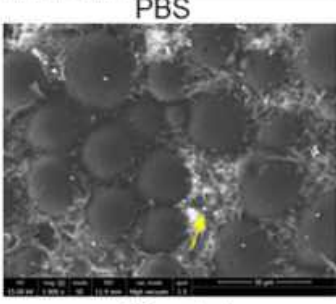

$10 \mu \mathrm{g} / \mathrm{mL}$

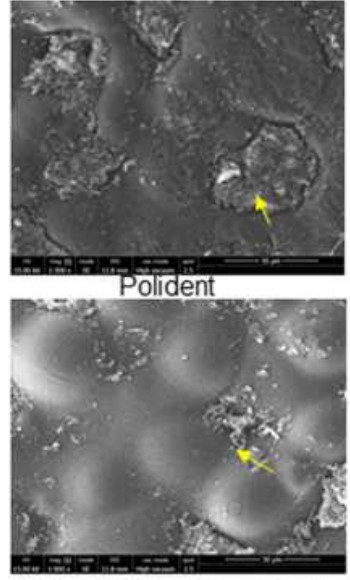

$20 \mu \mathrm{g} / \mathrm{mL}$ of AgBr-NP@CTMAB

Figure 7 C. albicans biofilm on PMMA soaked in PBS, dental cleaner (Polident), and AgBr-NP@CTMAB (concentrations of I, 2, 5, 10, $20 \mu \mathrm{gg} / \mathrm{m} / \mathrm{mL}$ ) for different times: 30 $\min (\mathbf{A})$ and $8 \mathrm{~h}(\mathbf{B})$. SEM (C) images (1000x) show the anti-biofilm action on PMMA incubated in different solutions after $8 \mathrm{~h}$. The scale bar is $50 \mu \mathrm{m}$ and the yellow arrow showed the remained $C$. albicans biofilm.

A

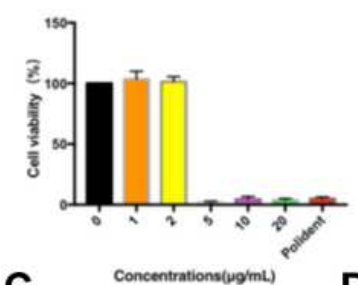

C

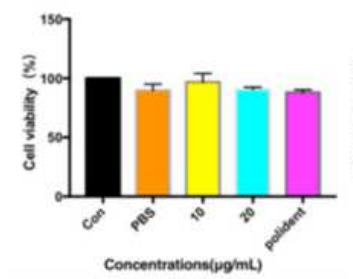

B

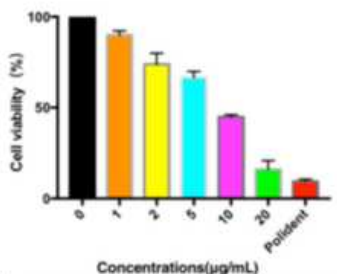

D

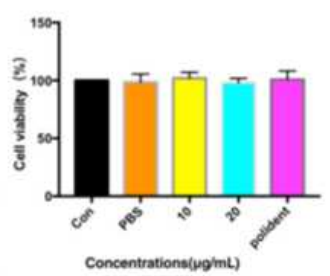

E

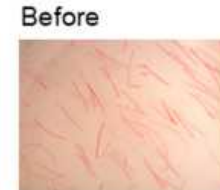

\section{After}

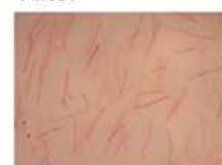

PBS
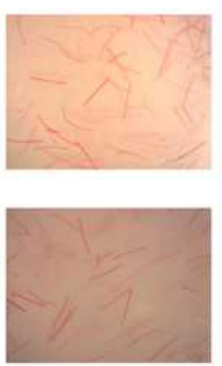

Polident
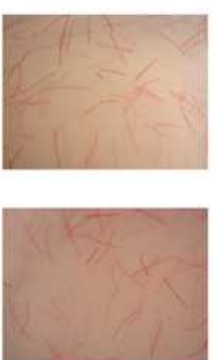

$10 \mu \mathrm{g} / \mathrm{mL}$
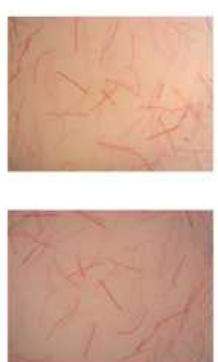

$20 \mu \mathrm{g} / \mathrm{mL}$

Figure 8 Cytotoxicity of AgBr-NP@CTMAB and color change of PMMA specimens. (A and B) Different concentrations of AgBr-NP@CTMAB were added directly to the culture medium and the cell viability of HOECs $(\mathbf{A}, \mathrm{P}<0.001$ for $5 \mu \mathrm{g} / \mathrm{mL}, 10 \mu \mathrm{g} / \mathrm{mL}, 20 \mu \mathrm{g} / \mathrm{mL} \mathrm{AgBr}-\mathrm{NP} @ \mathrm{CTMAB}$, and Polident when compared with control) and HGFs (B, P<0.0I for $2 \mu \mathrm{g} / \mathrm{mL}, 5 \mu \mathrm{g} / \mathrm{mL}, 10 \mu \mathrm{g} / \mathrm{mL}, 20 \mu \mathrm{g} / \mathrm{mL}$ of AgBr-NP@CTMAB, and Polident when compared with control) was measured by CCK-8 assay. (C and D) The residual cytotoxicity of AgBr-NP@CTMAB after washing 3 times with PBS on HOECs (C, P>0.05 among all groups by one way ANOVA) and HGFs (D, $\mathrm{P}>0.05$ among all groups by one way ANOVA) was measured by CCK-8 assay. (E) Color change of PMMA specimens after a repeated immersion cycles in AgBr-NP @CTMAB solutions for 7 days. 


\section{Disclosure}

The authors declare no potential competing interests in this work.

\section{References}

1. Cierech M, Kolenda A, Grudniak AM, et al. Significance of polymethylmethacrylate (PMMA) modification by zinc oxide nanoparticles for fungal biofilm formation. Int $J$ Pharm. 2016;510(1):323-335. doi:10.1016/j.ijpharm.2016.06.052

2. Chen R, Han Z, Huang Z, et al. Antibacterial activity, cytotoxicity and mechanical behavior of nano-enhanced denture base resin with different kinds of inorganic antibacterial agents. Dent Mater J. 2017;36 (6):693-699. doi:10.4012/dmj.2016-301

3. Heidrich D, Fortes CBB, Mallmann AT, Vargas CM, Arndt PB, Scroferneker ML. Rosemary, castor oils, and propolis extract: activity against Candida albicans and alterations on properties of dental acrylic resins. J Prosthodont. 2019;28(2):e863-e868. doi:10.1111/jopr.12746

4. Furletti VF, Teixeira IP, Obando-Pereda G, et al. Action of Coriandrum sativum L. Essential oil upon oral candida albicans biofilm formation. Evid Based Complement Alternat Med. 2011;2011:985832. doi:10.115 $5 / 2011 / 985832$

5. Jalal M, Ansari MA, Ali SG, Khan HM, Rehman S. Anticandidal activity of bioinspired $\mathrm{ZnO}$ NPs: effect on growth, cell morphology and key virulence attributes of Candida species. Artif Cells Nanomed Biotechnol. 2018;46(sup1):912-925. doi:10.1080/21691401.2018. 1439837

6. da Silva WJ, Seneviratne J, Samaranayake LP, Del Bel Cury AA. Bioactivity and architecture of Candida albicans biofilms developed on poly(methyl methacrylate) resin surface. J Biomed Mater Res B Appl Biomater. 2010;94(1):149-156. doi:10.1002/jbm.b.31635

7. Shibata T, Hamada N, Kimoto K, et al. Antifungal effect of acrylic resin containing apatite-coated $\mathrm{TiO} 2$ photocatalyst. Dent Mater J. 2007;26(3):437-444. doi:10.4012/dmj.26.437

8. Dias IJ, Trajano ERIS, Castro RD, Ferreira GLS, Medeiros HCM, Gomes DQC. Antifungal activity of linalool in cases of Candida spp. isolated from individuals with oral candidiasis. Braz J Biol. 2018;78 (2):368-374. doi:10.1590/1519-6984.171054

9. Fukunishi M, Inoue Y, Morisaki H, Kuwata H, Ishihara K, Baba K. A polymethyl methacrylate-based acrylic dental resin surface bound with a photoreactive polymer inhibits accumulation of bacterial plaque. Int $J$ Prosthodont. 2017;30(6):533-540. doi:10.11607/ ijp. 5332

10. de Souza RF, de Freitas Oliveira Paranhos H, Lovato da Silva CH, Abu-Naba'a L, Fedorowicz Z, Gurgan CA. Interventions for cleaning dentures in adults. Cochrane Database Syst Rev. 2009;4:CD007395.

11. Martínez A, Catalán A, Rojas N, et al. In vitro effectiveness of a terpenic denture cleanser on old biofilm surfaces. J Prosthodont. 2018;27(1):57-62. doi:10.1111/jopr.12531

12. Skupien JA, Valentini F, Boscato N, Pereira-Cenci T. Prevention and treatment of Candida colonization on denture liners: a systematic review. J Prosthet Dent. 2013;110(5):356-362. doi:10.1016/j. prosdent.2013.07.003

13. de Andrade IM, Cruz PC, da Silva CH, et al. Effervescent tablets and ultrasonic devices against Candida and mutans streptococci in denture biofilm. Gerodontology. 2011;28(4):264-270. doi:10.1111/ j.1741-2358.2010.00378.x

14. Hayran Y, Sarikaya I, Aydin A, Tekin YH. Determination of the effective anticandidal concentration of denture cleanser tablets on some denture base resins. J Appl Oral Sci. 2018;26:e20170077. doi:10.1590/1678-7757-2017-0077

15. Rezvani E, Rafferty A, McGuinness C, Kennedy J. Adverse effects of nanosilver on human health and the environment. Acta Biomater. 2019;94:145-159. doi:10.1016/j.actbio.2019.05.042
16. Khurana C, Vala AK, Andhariya N, Pandey OP, Chudasama B. Antibacterial activity of silver: the role of hydrodynamic particle size at nanoscale. J Biomed Mater Res A. 2014;102(10):3361-3368. doi:10.1002/jbm.a.35005

17. Huang QT, He JW, Lin ZM, Liu F, Lassila LV, Vallittu PK. Physical and chemical properties of an antimicrobial Bis-GMA free dental resin with quaternary ammonium dimethacrylate monomer. $J$ Mech Behav Biomed. 2016;56:68-76. doi:10.1016/j.jmbbm.2015.10.028

18. Farah S, Aviv O, Laout N, et al. Qua- ternary ammonium polyethylenimine nanoparticles for treating bacterial contaminated water. Colloids Surf B Biointerfaces. 2015;128:614-619. doi:10.1016/j. colsurfb.2015.03.006

19. Nam KY. Characterization and bacterial anti-adherent effect on modified PMMA denture acrylic resin containing platinum nanoparticles. J Adv Prosthodont. 2014;6(3):207-214. doi:10.4047/ jap.2014.6.3.207

20. Divya M, Vaseeharan B, Abinaya M, et al. Biopolymer gelatin-coated zinc oxide nanoparticles showed high antibacterial, antibiofilm and anti-angiogenic activity. $J$ Photochem Photobiol B. 2018; 178:211-218. doi:10.1016/j.jphotobiol.2017.11.008

21. Segall MD, Lindan PJD, Probert MJ, et al. First-principles simulation: ideas, illustrations and the CASTEP code. J Phys Condens Matter. 2002;14(11):2717-2744. doi:10.1088/0953-8984/14/11/301

22. Stewart JC, Matthew DS, Chris JP, et al. First principles methods using CASTEP. Z Kristallogr-Cryst Mater. 2005;220:567-667.

23. Regis RR, Della Vecchia MP, Pizzolitto AC, et al. Antimicrobial properties and cytotoxicity of an antimicrobial monomer for application in prosthodontics. J Prosthodont. 2012;21:283-290. doi:10.1111/ j.1532-849X.2011.00815.x

24. da Silva FC, Kimpara ET, Mancini MN, Balducci I, Jorge AO, KogaIto $\mathrm{CY}$. Effectiveness of six different disinfectants on removing five microbial species and effects on the topographic characteristics of acrylic resin. J Prosthodont. 2008;17(8):627-633. doi:10.1111/ j.1532-849X.2008.00358.x

25. Cai R, Tao G, He H, et al. One-step synthesis of silver nanoparticles on polydopamine-coated sericin/polyvinyl alcohol composite films for potential antimicrobial applications. Molecules. 2017;22:pii: E721. doi:10.3390/molecules22050721

26. Martínez-Martínez MA, Hernandez-Delgadillo R, Abada BS, et al. Antimicrobial potential of bismuth lipophilic nanoparticles embedded into chitosan-based membrane. Dent Mater J. 2019;38(4):611-620. doi:10.4012/dmj.2018-173

27. Cierech M, Osica I, Kolenda A, et al. Mechanical and physicochemical properties of newly formed ZnO-PMMA nanocomposites for denture bases. Nanomaterials. 2018;8(5):305. doi:10.3390/nano8050305

28. de Castro DT, Valente ML, Agnelli JA, et al. In vitro study of the antibacterial properties and impact strength of dental acrylic resins modified with a nanomaterial. J Prosthet Dent. 2016;115:238-246. doi:10.1016/j.prosdent.2015.09.003

29. Freitasfernandes FS, Cavalcanti YW, Ricomini Filho AP, et al. Effect of daily use of an enzymatic denture cleanser on Candida albicans biofilms formed on polyamide and poly(methyl methacrylate) resins: an in vitro study. $J$ Prosthet Dent. 2014;112(6):1349-1355. doi:10.1016/j.prosdent.2014.07.004

30. Zamperini CA, Machado AL, Vergani CE, et al. Adherence in vitro of Candida albicans to plasma treated acrylic resin. Effect of plasma parameters, surface roughness and salivary pellicle. Arch Oral Biol. 2010;55(10):763-770. doi:10.1016/j.archoralbio.2010.06.015

31. Arias-Moliz MT, Ferrer-Luque CM, González-Rodríguez MP, Navarro-Escobar E, de Freitas MF, Baca P. Antimicrobial activity and enterococcus faecalis biofilm formation on chlorhexidine varnishes. Med Oral Patol Oral Cir Bucal. 2012;17(4):e705-709. doi:10.4317/medoral.17680

32. Queiroz JR, Fissmer SF, Koga-Ito CY, et al. Effect of diamond-like carbon thin film coated acrylic resin on candida albicans biofilm formation. J Prosthodont. 2013;22:451-455. doi:10.1111/jopr.12029 
33. Cao W, Zhang Y, Wang X, et al. Development of a novel resin-based dental material with dual biocidal modes and sustained release of $\mathrm{Ag}$ +ions based on photocurable core-shell $\mathrm{AgBr} /$ cationic polymer nanocomposites. J Mater Sci Mater Med. 2017;28(7):103. doi:10.1007/s10856-017-5918-3

34. Wei Y, Sun J, Men Q, et al. Toxic effects of four kinds of dental restorative materials on fibroblast HGF-1 and impacts on expression of Bcl-2 and Bax genes. Exp Ther Med. 2018. doi:10.3892/etm.2018.6705

35. Zeng X, Xiong S, Zhuo S, et al. Nanosilver/poly (dl-lactic-coglycolic acid) on titanium implant surfaces for the enhancement of antibacterial properties and osteoinductivity. Int $J$ Nanomedicine. 2019;14:1849-1863. doi:10.2147/IJN.S190954

36. Koseki Y, Tanaka R, Murata H. Development of antibacterial denture cleaner for brushing containing tea tree and lemongrass essential oils Dent Mater J. 2018;37(4):659-666. doi:10.4012/dmj.2017-295

37. Ghazal ARA, Idris G, Hajeer MY, Alawer K, Cannon RD. Efficacy of removing Candida albicans from orthodontic acrylic bases: an in vitro study. BMC Oral Health. 2019;19(1):71. doi:10.1186/ s12903-019-0765-x

38. Tsutsumi C, Takakuda K, Wakabayashi N. Reduction of Candida biofilm adhesion by incorporation of prereacted glass ionomer filler in denture base resin. $J$ Dent. 2016;44:37-43. doi:10.1016/j. jdent.2015.11.010

39. Zoccolotti JO, Tasso CO, Arbeláez MIA, et al. Properties of an acrylic resin after immersion in antiseptic soaps: low-cost, easy-access procedure for the prevention of denture stomatitis. PLoS One. 2018;13(8):e0203187. doi:10.1371/journal.pone.0203187
40. Tsutsumi-Arai C, Takakusaki K, Arai Y, et al. Grapefruit seed extract effectively inhibits the Candida albicans biofilms development on polymethyl methacrylate denture-base resin. PLoS One. 2019;14: e0217496. doi:10.1371/journal.pone.0217496

41. Kumar PJ, Kwang-Hyun B. Antibacterial Activity and Synergistic Antibacterial Potential of Biosynthesized Silver Nanoparticles against Foodborne Pathogenic Bacteria along with its Anticandidal and Antioxidant Effects. Front Microbiol. 2017;08(1):167-281.

42. Petr S, Libor K, Ales P, et al. Comparative Study of antimicrobial activity of $\mathrm{AgBr}$ and $\mathrm{Ag}$ nanoparticles (NPs). PLoS One. 2015;10 (3):0119202

43. Li Z, Wang W, Zhu L. Effects of mixed surfactants on the bioaccumulation of polycyclic aromatic hydrocarbons (PAHs) in crops and the bioremediation of contaminated farmlands. Sci Total Environ. 2019;646:1211-1218. doi:10.1016/j.scitotenv.2018.07.349

44. Zhang Y, Chen YY, Huang L, et al. The antifungal effects and mechanical properties of silver bromide/cationic polymer nano-composite-modified Poly-methyl methacrylate-based dental resin. Sci Rep. 2017;7(1):1547-1560. doi:10.1038/s41598-01701686-4

45. Kurt A, Erkose-Genc G, Uzun M, et al. The effect of cleaning solutions on a denture base material: elimination of candida albicans and alteration of physical properties. J Prosthodont. 2018;27 (6):577-583. doi:10.1111/jopr.12539
International Journal of Nanomedicine

\section{Publish your work in this journal}

The International Journal of Nanomedicine is an international, peerreviewed journal focusing on the application of nanotechnology in diagnostics, therapeutics, and drug delivery systems throughout the biomedical field. This journal is indexed on PubMed Central, MedLine, CAS, SciSearch ${ }^{\circledR}$, Current Contents ${ }^{\circledR} /$ Clinical Medicine,

\section{Dovepress}

Journal Citation Reports/Science Edition, EMBase, Scopus and the Elsevier Bibliographic databases. The manuscript management system is completely online and includes a very quick and fair peer-review system, which is all easy to use. Visit http://www.dovepress.com/ testimonials.php to read real quotes from published authors. 